\title{
Uma Ferramenta para Apoio ao Ensino de Estrutura de Dados utilizando Interação Natural
}

\author{
Anthony F. La Marca, Marcus Vinícius B. Da Silva, Windelimarcos F. De Borba, \\ Instituto Ciências Exatas e da Terra (ICET) - Universidade Federal de Mato Grosso \\ (UFMT) - Barra do Garças - MT. \\ (anthonyferreiralamarca, marcusbrito17, windelimarcos)@gmail.com
}

\begin{abstract}
With the appearance of studies in Human-Computer Interaction (HCI) area, several tools which provided users ease of interaction with the machines were created. Due to the large current success of the video game industry, many of these tools are designed for HCI, for instance, the Kinect device. These tools have great potential due to new technologies, making them viable for studies in academia. Therefore, this paper presents the creation of a tool using Kinect device to assist in teaching data structure. The idea of the tool is to increase student interaction with the system via mechanisms that provide natural interaction, providing a tool to aid the teaching process and learning.
\end{abstract}

Resumo. Com o surgimento de estudos na área de Interação HumanoComputador, foram criadas diversas ferramentas que proporcionavam aos usuários maior facilidade de interação com as máquinas. Devido ao grande sucesso atual do setor de jogos eletrônicos, muitas dessas ferramentas são designadas a esse meio, como, por exemplo, o dispositivo Kinect. Tais ferramentas possuem grande potencial, devido às novas tecnologias associadas, tornando-as viáveis para os estudos no meio acadêmico. Desta forma, o trabalho aborda a criação de uma ferramenta utilizando o dispositivo Kinect para auxiliar no ensino de estrutura de dados. A ideia da ferramenta é aumentar a interação dos alunos para/com o sistema por meio de mecanismos que ofereçam a interação natural, proporcionando uma ferramenta de auxílio ao processo de ensino e aprendizagem.

\section{Introdução}

Os desafios no processo de ensino e aprendizagem são constantemente encarados por educadores e seus alunos, buscando transmitir e adquirir os conhecimentos envolvidos. Em muitos casos, os métodos tradicionais, utilizados nesta tarefa, não são tão eficazes, pois cada aluno possui suas próprias características, interesses, capacidades e necessidades de aprendizagem. Desta forma, faz-se necessário desenvolver meios em que o alcance ao interesse seja maximizado, para que assim, obtenha-se um melhor aproveitamento do ensino.

Um dos grandes diferenciais observados atualmente no ensino é o de uso de tecnologias computacionais, na qual é possível obter maior atenção dos alunos por oferecerem recursos que aumentem o realismo e interação para/com o ensino. Com o avanço tecnológico, observou-se que a interação homem-máquina aumentou significativamente, proporcionando melhor interação, imersão e navegação entre o homem e sistemas computadorizados. Neste contexto, rastreadores de movimentos 
V Congresso Brasileiro de Informática na Educação (CBIE 2016)

Anais dos Workshops do V Congresso Brasileiro de Informática na Educação (CBIE 2016)

"casados" com aplicações de Realidade Virtual, surgiram para trazer inovações ao mundo de pesquisa e de ensino.

Entre os rastreadores disponíveis, o Microsoft Kinect, lançado em 2010, proporcionava aos usuários um comportamento livre, sem a necessidade de controle, apenas utilizando o próprio movimento do corpo, diferente de outros lançamentos da época. O que este rastreador de movimento proporciona aos usuários, chamamos de Interação Natural, sendo um sistema capaz de entender ações naturais do ser humano e repassá-las em tempo real para o ambiente tridimensional, modificando-o (Valli, 2005).

Diante desse cenário e com o intuito de contribuir com o processo de ensino e aprendizagem, o trabalho propõe o desenvolvimento de uma ferramenta, utilizando o dispositivo Kinect como uma alternativa, a fim de proporcionar melhor interação, imersão e envolvimento para o ensino direcionado às temáticas de Estruturas de Dados.

\section{Motivação}

Foi observado, ao longo de mais de cinco anos, na Universidade Federal de Mato Grosso - campus Araguaia, que o número de alunos reprovados na disciplina de Estrutura de Dados representava uma parcela significativa em relação à quantidade matriculada, conforme ilustra a Figura 1.

\begin{tabular}{|c|c|c|c|}
\hline Ano & Disciplina & Total de Matriculados & Total Reprovados \\
\hline 2009 & ED1 & 11 & 7 \\
\hline 2010 & ED1 & 53 & 40 \\
\hline 2011 & ED1 & 56 & 44 \\
\hline 2012 & ED1 & 43 & 22 \\
\hline 2013 & ED1 & 48 & 26 \\
\hline 2014 & ED1 & 45 & 24 \\
\hline 2015 & ED1 & 45 & 21 \\
\hline
\end{tabular}

Figura 1 - Índice de Reprovações (SIGA, 2016)

Diversas discursões, entre professores e alunos, apontaram que a dificuldade no processo de ensino das temáticas da disciplina, se dá devido à complexidade em abstrair os conteúdos abordados. Fator esse, remete ao desafio em expor as estruturas de dados e suas manipulações, que ocorrem de forma dinâmica e implícita no interior dos dispositivos de processamento dos computadores, como em registradores e na memória principal, utilizando as ferramentas tradicionais de ensino, como a lousa e o quadro negro, que em sua maioria a representação se dá de forma estática.

Representar de forma abstrata e dinâmica eventos que ocorrem dentro da memória principal de um computador, como endereçamento de ponteiros e organização dos dados nas estruturas, tem sido o principal objetivo do desenvolvimento desse trabalho. A fim de tornar o processo de aprendizagem mais atrativo, desenvolver uma ferramenta que ao mesmo tempo mescle a possibilidade de abstrair as estruturas de dados e torná-las mais intuitivas para o ensino, se torna evidente.

\section{Interação Humano-Computador (IHC)}

A Interação Humano-Computador (IHC) surgiu por voltar de 1980, junto com a criação dos computadores pessoais. É uma área multidisciplinar composta por psicologia, ciência da computação, linguísticas, artes, dentre outras, com o objetivo de criar uma melhor forma de comunicação entre o ser humano e computadores (Valli, 2005). Com 
V Congresso Brasileiro de Informática na Educação (CBIE 2016)

Anais dos Workshops do V Congresso Brasileiro de Informática na Educação (CBIE 2016)

isso, foram iniciados estudos sobre interfaces gráficas mais intuitivas, dispositivos para uma interação mais rápida e precisa. Desta Forma, as chamadas Interfaces Naturais do Usuário ou Natural User Interface (NUI), foram criadas com o propósito de possibilitar ao usuário fácil controle dessas interfaces, ambientes virtuais, por meio de comandos que já são comuns em seu dia-a-dia.

É comum que o ser humano utilize o auxílio da linguagem gestual para se comunicar, por ser uma forma natural e simples. Assim, a ferramenta incorpora os benefícios da NUI através do dispositivo Kinect, designado a realizar leituras das ações naturais dos usuários, como gestos, expressões e movimentos (Valli, 2005).

\section{Dispositivos Rastreadores - Microsoft Kinect}

Os dispositivos de rastreamentos são utilizados para acompanhar a posição do corpo e os movimentos do usuário, assim como a posição de outros objetos por ele utilizados. Após a captação destes movimentos, eles são repassados ao mundo tridimensional, modificando-o em tempo real, além de um feedback para o usuário.

Um destes dispositivos é o Microsoft Kinect, lançado com o objetivo de mudar a forma de interação das pessoas com os jogos, sendo uma tecnologia onde as pessoas não teriam necessidade de utilizar controles físicos para jogar, mas sim, o próprio movimento do corpo.

Além da tecnologia da câmera infravermelha, o Kinect possui uma câmera RGB (Red, Green and Blue) e quatro microfones utilizados para o comando de voz. Um dos principais atrativos da tecnologia do Kinect é a sua capacidade de diferenciar seres humanos dos demais objetos no ambiente (Microsoft, 2014).

Devido ao grande sucesso do dispositivo na área acadêmica, a Microsoft lançou uma versão específica para computador e disponibilizou um Software Development Kit (SDK) com diversas ferramentas prontas para auxiliar os desenvolvedores, tornando-o uma ferramenta de grande potencial para aplicações com Interação Natural em diversas áreas. Dessa forma, o Kinect está sendo inserido, além do ambiente de jogos, em pesquisas na área de medicina, engenharia, segurança, e principalmente na área de ensino. (Medeiros, 2012).

\section{Estrutura de Dados}

O mundo computacional, desde sua criação durante a segunda guerra mundial, onde surgiram os primeiros computadores conhecidos atualmente, sofre constantes evoluções criando novas perspectivas. Como consequência dessas evoluções, a quantidade de dados a serem manipulados e armazenados teve um aumento extraordinário, tornando a eficiência de como controlá-los um fator de grande importância. Para resolver esse problema, começaram a criar novas técnicas para melhorar o aproveitamento de memória e de processamento para o controle desses dados. Essas técnicas foram chamadas de estrutura de dados, que segundo Laureano, nada mais é, do que formas de armazenamento utilizadas no mundo real adaptadas para o mundo computacional com a finalidade de otimizar a manipulação e o tratamento de dados eletronicamente (Laureano, 2012). 
V Congresso Brasileiro de Informática na Educação (CBIE 2016)

Anais dos Workshops do V Congresso Brasileiro de Informática na Educação (CBIE 2016)

Neste trabalho foram utilizadas as seguintes estruturas de dados: pilha, fila, lista simplesmente encadeada e as árvores: binária, balanceada pela altura (AVL) e de múltiplos filhos (M-ária).

\section{Metodologia}

Com a proposta de desenvolver uma ferramenta que utilize as tecnologias de imersão, interação e envolvimento dos usuários com o ambiente virtual, a fim de tornar o processo de aprendizagem mais dinâmico e atrativo, elementos como: Interação Humano-Computador e dispositivos de rastreamentos, foram estudados e abordados no trabalho.

Neste âmbito, foi desenvolvida uma ferramenta utilizando a linguagem de programação C\# com o ambiente de desenvolvimento Visual Studio 2012, devido ao SDK ter sido disponibilizado oficialmente pela fabricante (Microsoft) para este ambiente.

As principais tarefas do sistema são inserção e remoção de elementos nas estruturas citadas acima, além de representações gráficas, animações e comandos via interação natural, proporcionando imersão e envolvimento com o sistema virtual.

$\mathrm{Na}$ interface gráfica, todos os objetos devem estar dentro da área de um componente chamado KinectRegion, para que possam ser controlados por meio de interações com o Kinect. Além deste, o SDK fornece o KinectScrollViewers e o KinectTileButtons, que respectivamente representam as barras de rolagem e os botões, ambos acionados pelo dispositivo de rastreamento através dos movimentos dos usuários.

Dentro da área do KinectRegion, onde os objetos estão contidos, é capturado automaticamente o posicionamento de uma das mãos do usuário à frente do Kinect. Já nessa ferramenta, foram feitas alterações na Dynamic-Link Library (DLL), responsável pelo fluxo de interação, tornando possível realizar o rastreamento de ambas as mãos do usuário simultaneamente.

A interação com um botão, ou seja, pressioná-lo, é feita por meio do movimento de empurrar a mão em direção ao sensor Kinect, dando a impressão de estar realmente apertando um objeto. A KinectScrollViewer, ou barra de rolagem do Kinect, é manipulada por meio do fechamento da mão. Após fechar a mão é possível arrastar a barra na direção desejada. Assim, movimentos utilizados para os comandos devem ser bem distintos, pois a precisão do Kinect não é perfeita, podendo ocorrer confusão para o sistema em definir uma pose ou um movimento.

Há diversas técnicas para a detecção de movimentos, dentre elas a de redes neurais, a de comparação de um gesto previamente armazenado e a de detecção por algoritmos especializados (Cardoso, 2013).

Neste trabalho, foi utilizado o algoritmo especializado chamado keyframes. O método keyframe utiliza quadros-chaves, onde é definido valores a certos parâmetros que variam com o tempo em cada movimento, como posição ou cor. Por meio desses valores é calculada a evolução dos parâmetros em cada quadro de imagem em um determinado tempo (Gomide et al, 2009). Este limite entre os parâmetros do quadro inicial até o quadro no tempo final é utilizado para identificar a velocidade necessária para que o movimento seja aceito como um comando na ferramenta (Cardoso, 2013). 
V Congresso Brasileiro de Informática na Educação (CBIE 2016)

Anais dos Workshops do V Congresso Brasileiro de Informática na Educação (CBIE 2016)

O movimento de aceno com o braço direito é responsável pela inserção nas estruturas. Esse movimento é composto por uma lista de quadros com três poses, onde é necessário que inicialmente a mão direita do usuário esteja em uma posição maior que a posição do cotovelo direito em um eixo horizontal. Na pose seguinte, a mão e o cotovelo do usuário devem estar em uma mesma posição no eixo horizontal e a mão em uma posição superior em relação ao eixo vertical. Como última pose, a mão direita deve estar em uma posição inferior com relação ao eixo horizontal, conforme ilustra a Figura 2. Já o movimento de remoção é similar, mas deve ser executado utilizando o braço esquerdo. Com relação ao movimento para retornar ao menu principal, basta posicionar os braços à frente do corpo e baixá-los.
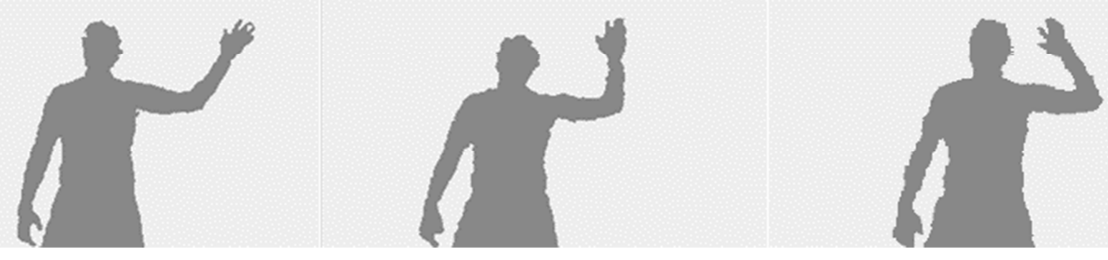

Figura 2 - Comando de inserção

\section{Descrição da Ferramenta}

Foi obtida uma ferramenta com interface simples e de fácil manuseio para o usuário, como é demonstrado no gráfico ilustrado na Figura 13. Efetuando movimentos diante do Kinect é possível utilizar toda a funcionalidade da ferramenta, dispensando a utilização de dispositivos convencionais, como mouse e teclado. A Figura 3 ilustra a interface inicial do sistema.

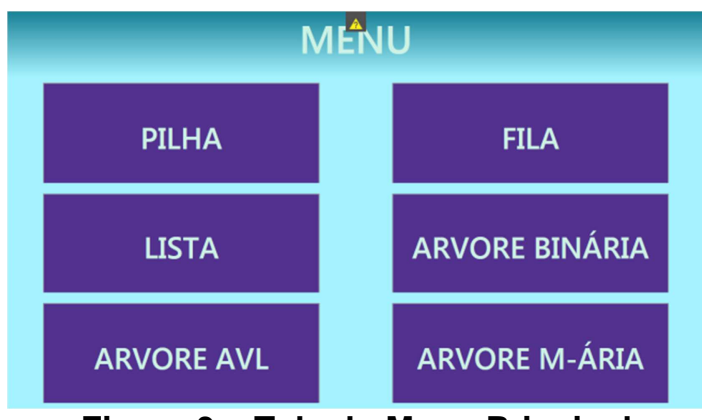

Figura 3 - Tela do Menu Principal

$\mathrm{Na}$ interface gráfica do menu principal são disponibilizados botões para selecionar as opções de temas disponíveis relacionados a disciplina de estrutura de dados. Dentre os temas a serem escolhidos estão a pilha, a fila, a lista e as árvores, conforme ilustra a Figura 3.

Em todas as interfaces há a presença de um quadro que contém os números que podem ser inseridos nas respectivas estruturas, além de botões para auxiliar na manipulação e navegação na interface. Todos os números são acionados via Interação Natural por meio do Kinect, bastando ir em direção ao número com a mão e realizar o movimento de "pressionar" para selecioná-lo. Após o número ser selecionado, basta acionar um dos botões, de inserção ou remoção, ou realizar algum dos movimentos de aceno para manipular a estrutura. Vale ressaltar que, todas as operações nas estruturas obedecem suas regras de manipulação. 
V Congresso Brasileiro de Informática na Educação (CBIE 2016)

Anais dos Workshops do V Congresso Brasileiro de Informática na Educação (CBIE 2016)

A Figura 4 apresenta as operações de inserção e remoção na estrutura Pilha, respectivamente. $\mathrm{Na}$ inserção, o novo elemento, por meio de animação, se desloca no eixo Y até alcançar o topo da pilha. Já na remoção, o deslocamento é realizado no eixo $\mathrm{X}$ e tem sua opacidade reduzida gradualmente até ser eliminado da interface.

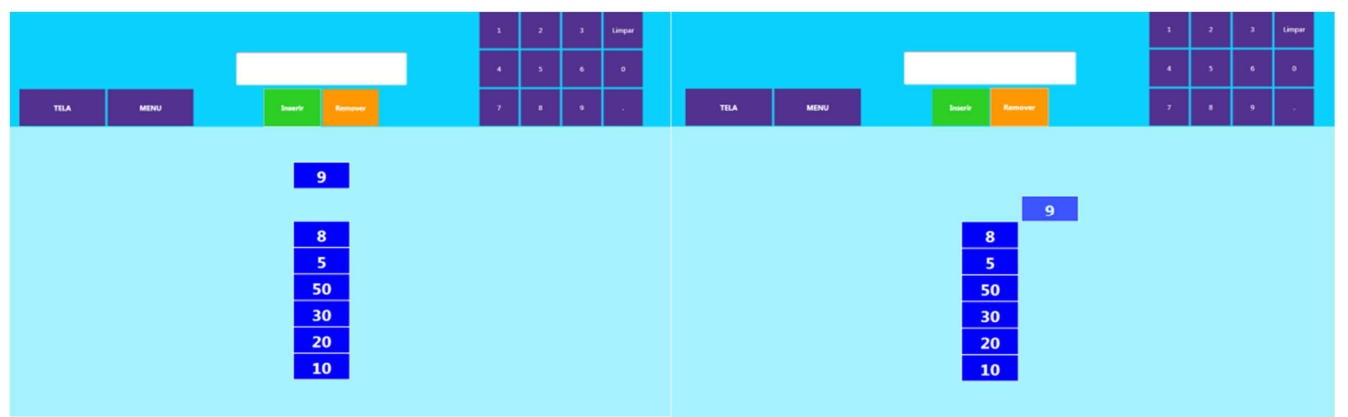

Figura 4 - Inserção e Remoção na Estrutura Pilha

$\mathrm{Na}$ estrutura Fila, conforme ilustra a Figura 5, as operações são realizadas idem a estrutura Pilha, no entanto, na inserção o deslocamento é feito no eixo $\mathrm{X}$ e na remoção no eixo Y, seguido do deslocamento de todos os elementos ao ponto inicial da fila.

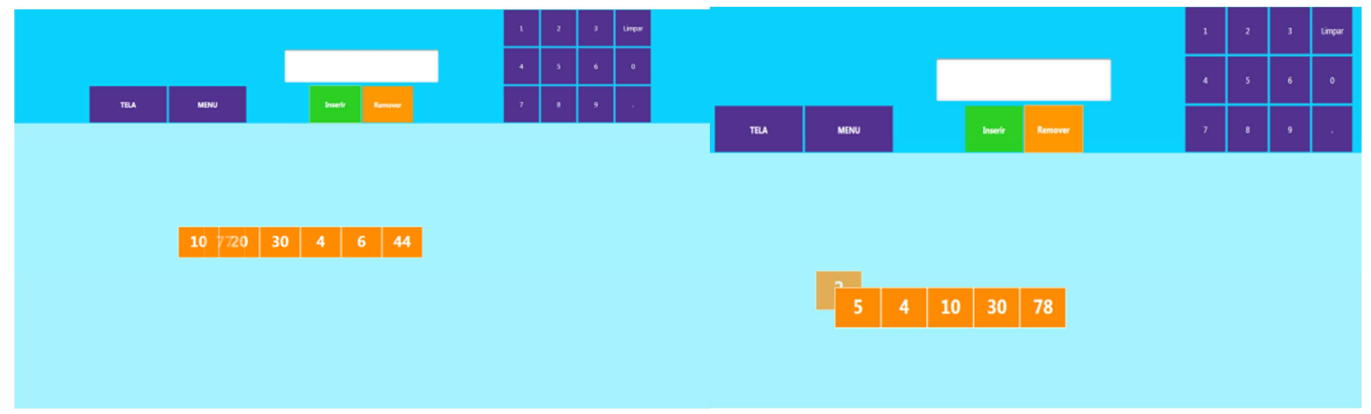

Figura 5 - Inserção e Remoção na Estrutura Fila

$\mathrm{Na}$ inserção, ao decorrer de seu deslocamento, o novo elemento fica parcialmente transparente até alcançar sua posição no fim da fila. A Figura 5, em sua primeira parte, ilustra o elemento 77 , com opacidade reduzida, se deslocando no eixo $\mathrm{X}$ até a sua posição. Já na segunda parte, mostra uma remoção onde o primeiro elemento da Fila é eliminado se deslocando no eixo Y, e ocorre o reposicionamento dos demais.

Caso ocorra a tentativa de uma inserção de um valor já existente em qualquer estrutura, o elemento presente é destacado, por meio de uma animação, conforme ilustra a Figura 6.

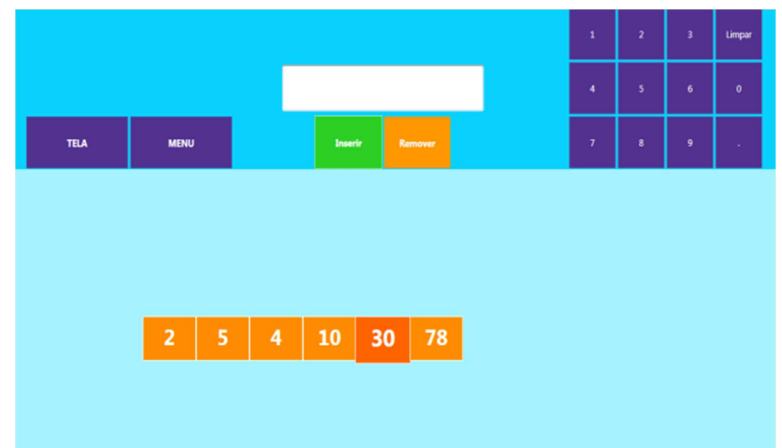

Figura 6 - Inserção Repetida do Valor 30 na Estrutura Fila

$\mathrm{Na}$ interface da estrutura Lista, as animações acontecem de forma semelhante à estrutura Fila. No entanto, com a possibilidade de inserção e remoção em qualquer 
V Congresso Brasileiro de Informática na Educação (CBIE 2016)

Anais dos Workshops do V Congresso Brasileiro de Informática na Educação (CBIE 2016)

posição, há o deslocamento dos demais elementos a partir da posição acionada, conforme ilustra a Figura 7. Além disso, possui um botão para alternar a entrada do usuário entre valor/posição, localizado acima dos campos de textos "valor" e "posição", respectivamente.

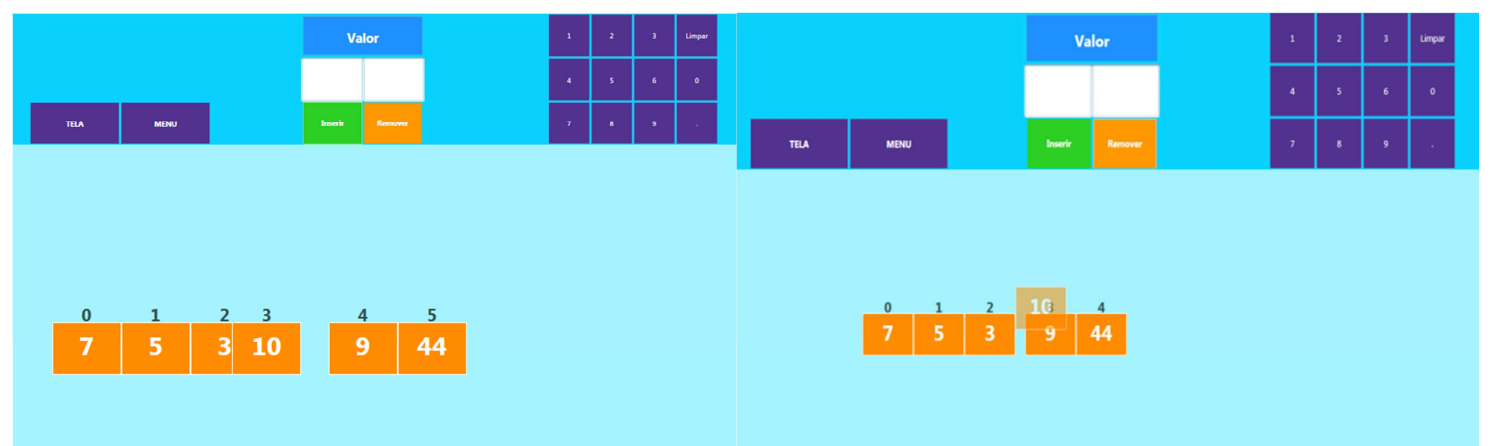

Figura 7 - Inserção e Remoção do valor 10 na Estrutura Lista

Nas estruturas do tipo árvore, o posicionamento de seus elementos são de forma análoga as ramificações de uma árvore, havendo um reposicionamento de acordo com o elemento a ser inserido ou removido. As operações de inserção e remoção na Árvore Binária podem ser vistas na Figura 8. Com a inserção ou remoção de um valor, a altura da árvore pode ser incrementada e seus elementos reposicionados. O caminho percorrido pelo novo elemento através dos nós possui a coloração dos ponteiros em vermelho, para demonstrar ao usuário o caminho que o nó percorreu até o seu destino.

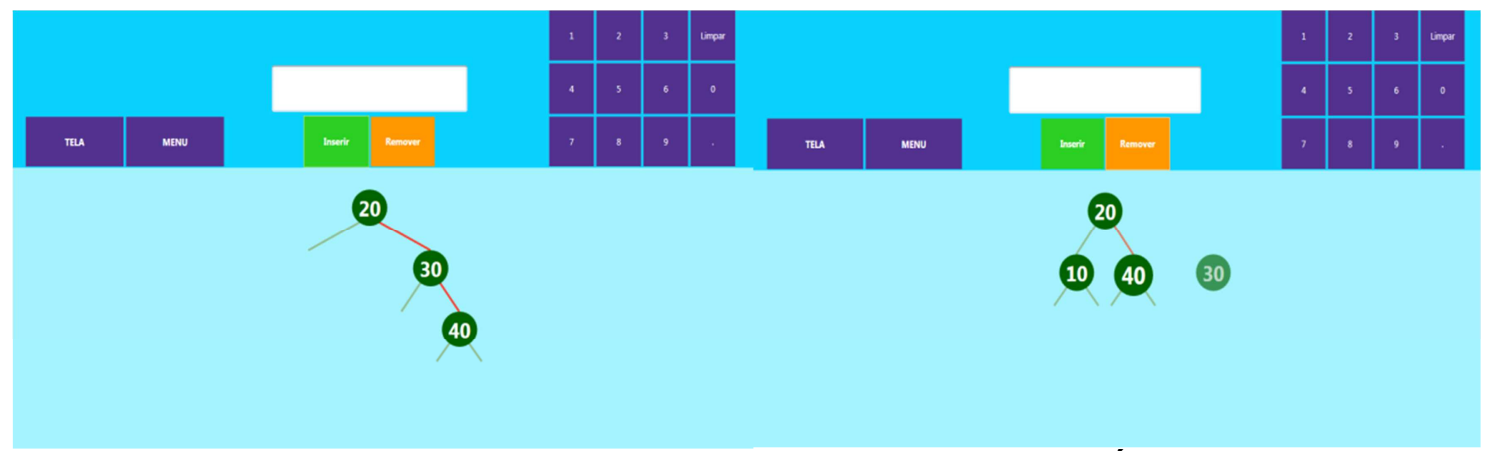

Figura 8 - Inserção do valor 40 e Remoção do valor 30 na Árvore Binária

As operações de inserção e remoção na Árvore de Múltiplos-Filhos ocorrem de forma semelhante à Árvore Binária, conforme ilustra a Figura 9.

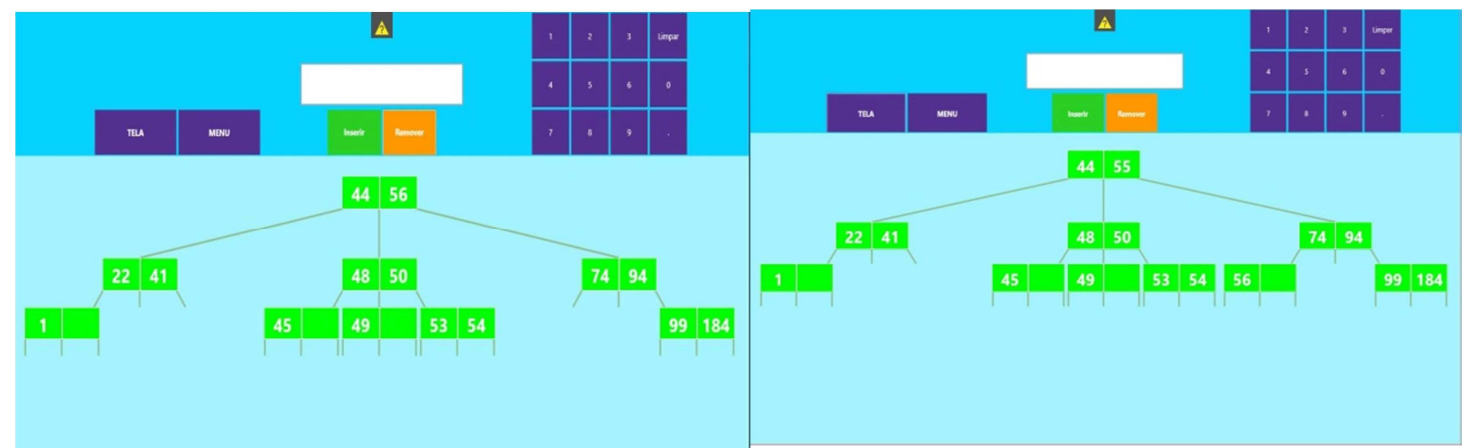

Figura 9 - Interface da Árvore de Múltiplos Filhos e Inserção do Nó 56 em sua Estrutura 
V Congresso Brasileiro de Informática na Educação (CBIE 2016)

Anais dos Workshops do V Congresso Brasileiro de Informática na Educação (CBIE 2016)

$\mathrm{Na}$ interface da árvore AVL, há a representação dos nós, de fatores de balanceamento e de rotações. A Figura 10 ilustra o estado da Árvore AVL, na qual não há a necessidade do reposicionamento dos nós, pois a árvore encontra-se balanceada.

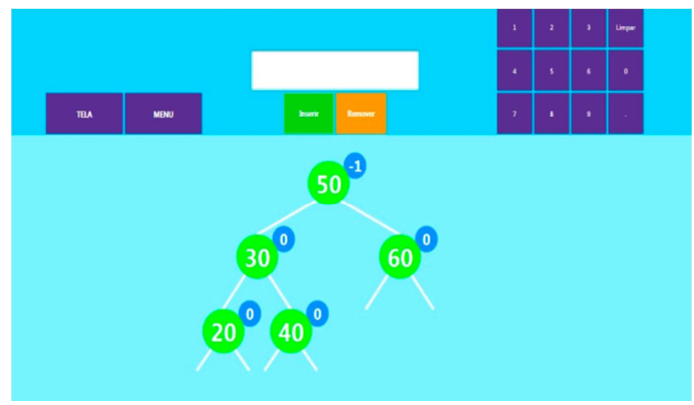

Figura 10 - Árvore AVL

Em outro estado da Árvore AVL, após a inserção de uma sequência de elementos, ocorre à necessidade de uma rotação. Isso, devido ao desbalanceamento da árvore, indicado na mudança das cores dos elementos e de seus fatores de carga, conforme ilustra a Figura 11a. A cor vermelha, no fator de carga, indica que o respectivo nó precisa ser rotacionado. A cor verde clara indica que o nó está em sua posição correta e a cor verde escuro, indica que o nó será reposicionado para a posição do nó de cor azul. Após o balanceamento, conforme ilustra a Figura 11b, observa-se que todos os nós encontram-se verdes claros com seus respectivos fatores de carga em azul.

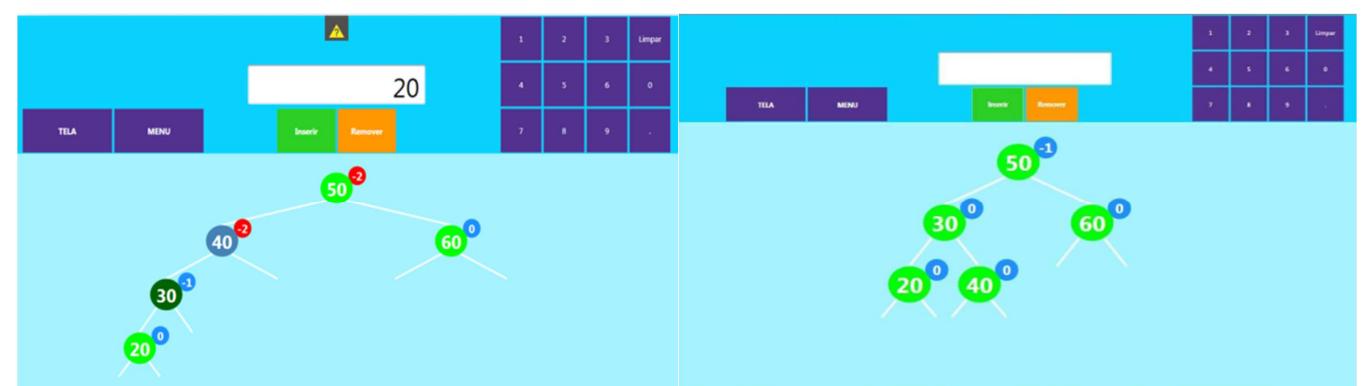

Figura 11a - Árvore AVL Desbalanceada Figura 11b - Árvore AVL Balanceada

\section{Resultado}

O teste e a avaliação da ferramenta foram realizados com turmas distintas de alunos, para obter informações quanto a sua eficiência e a sua utilidade. Por meio de demonstrações e da aplicação de questionários, tanto alunos que já haviam cursado a disciplina de Estrutura de Dados, quanto alunos que ainda não tinham conhecimento dos assuntos abordados, puderam avaliar e levantar suas opiniões e impressões sobre a ferramenta desenvolvida, o que foi primordial para a evolução da ferramenta. A Figura 12 ilustra uma aluna participando dos testes da ferramenta.

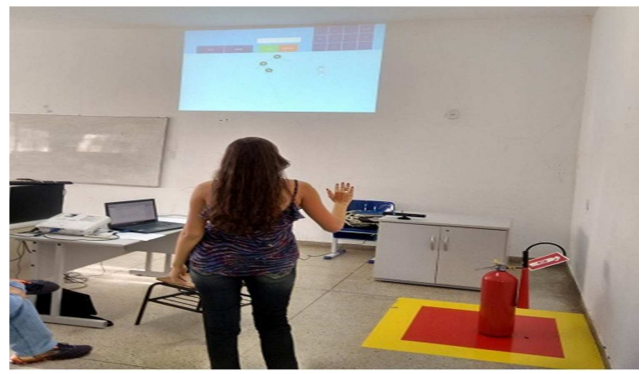

Figura 12 - Teste da Ferramenta 
V Congresso Brasileiro de Informática na Educação (CBIE 2016)

Anais dos Workshops do V Congresso Brasileiro de Informática na Educação (CBIE 2016)

Dentre os quarenta (40) colaboradores presentes na avaliação da ferramenta, cerca de $50 \%$ eram alunos cursando a disciplina, $40 \%$ alunos que já cursaram e $10 \%$ professores que ministram a disciplina. A participação dos colaboradores que já haviam cursado a disciplina de Estrutura de Dados foi adotada como parâmetro para avaliar a ferramenta em relação ao método tradicional de ensino.

O processo de avaliação aconteceu em três (3) etapas. A primeira etapa consistia na apresentação, demonstração e explicação da ferramenta para os colaboradores. Já na segunda etapa, os colaboradores que manifestaram interesse, tiveram a oportunidade de usar a ferramenta. Por fim, na terceira etapa, foi aplicado o questionário (geral) para a avaliação.

O questionário de avaliação consistia em responder perguntas relacionadas sobre os seguintes aspectos da ferramenta:

- Interface Gráfica: usabilidade, navegação, interatividade, dinamismo;

- Temática Abordada: Confiabilidade, Abstração, Intuitividade;

- Software em Geral: utilização, dinamismo, inovação.

Com base nas repostas dos tópicos citados a cima, cujos fatores de qualificação correspondiam em: muito pouco, pouco, razoável, bom e muito bom, foi possível avaliar a eficiência e a utilidade da ferramenta, além de levantar contribuições para futuras melhorias.

Contudo, após todos os testes e avaliações aplicadas em diferentes turmas de alunos e alguns professores que lecionam a disciplina de Estrutura de Dados, obteve-se o nível de aceitação e eficiência da ferramenta desenvolvida em relação à sua proposta inicial, conforme o gráfico ilustrado na Figura 13.

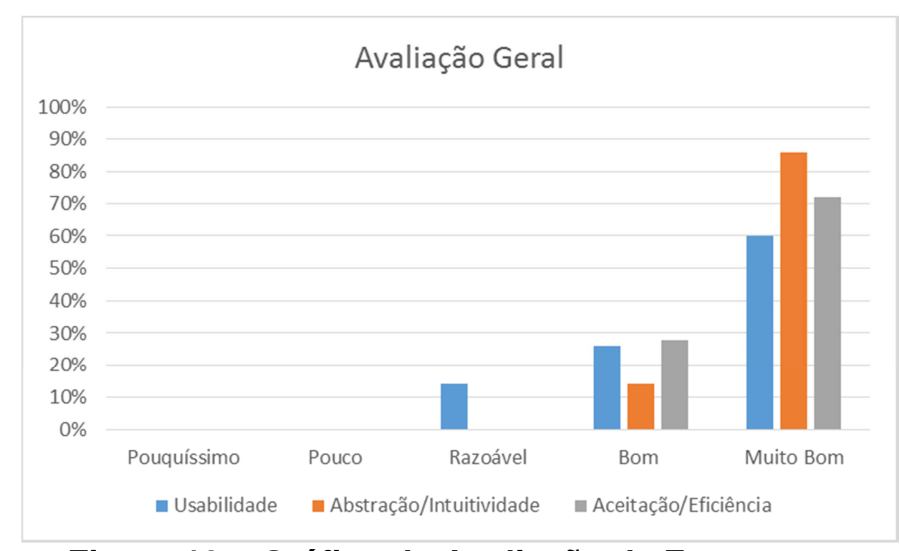

Figura 13 - Gráfico de Avaliação da Ferramenta

A Figura 13 demonstra a avaliação geral da ferramenta com a abordagem dos principais tópicos: Usabilidade geral do sistema, Abstração e Intuitividade das temáticas apresentadas, e Aceitação e Eficiência do Sistema; os quais tiveram em sua maioria, respostas que indicam a satisfação dos objetivos em muito boa, na margem dos 60 a $90 \%$.

\section{Conclusão}

O levantamento bibliográfico foi necessário para o desenvolvimento da ferramenta, pois foram apresentadas as justificativas, as estruturas e as tecnologias que proporcionaram o seu desenvolvimento. 
V Congresso Brasileiro de Informática na Educação (CBIE 2016)

Anais dos Workshops do V Congresso Brasileiro de Informática na Educação (CBIE 2016)

A facilidade em compreender a partir de imagens, animações e a possibilidade de interagir com elas, foram os principais fatores para incentivar o desenvolvimento da ferramenta. Uma vez que é possível visualizar e acompanhar as modificações nas estruturas de dados a partir de imagens gráficas, dinâmicas e interativas, em um ambiente integrado e em tempo real, torna sua compreensão mais intuitiva.

Com base na avaliação realizada com alunos e professores, foi possível observar o potencial da ferramenta para auxiliar no ensino e aprendizagem das temáticas da disciplina de Estrutura de Dados, além de feedbacks positivos por parte dos alunos quanto à sua compreensão, devido a abstração, clareza e intuitividade com que as estruturas são abordadas na ferramenta desenvolvida.

Portanto, o uso do dispositivo Kinect foi primordial para aprimorar a interação da ferramenta com os usuários, maximizando a experiência de uso em relação aos dispositivos convencionais, como mouse e teclado.

Como trabalhos futuros, novas estruturas podem ser incorporadas ao trabalho, devido a sua programação modular, além da substituição do dispositivo Kinect para a versão Kinect One, que possibilita mais recursos e precisão para a manipulação e o rastreamento.

\section{Referências}

Cardoso, Gabriel s. Microsoft Kinect: crie aplicações interativas com o microsoft kinect. Casa do código. São Paulo, 2013.

Figueiredo, Lucas; Souza, Pedro; Simões, Francisco; Roberto, rRafael; Teichrieb, Veronica. Interação natural a partir de rastreamento de mãos. Universidade Federal de Pernambuco. Simpósio de realidade virtual. Rio de Janeiro, 2012.

Gomide, João v. b; Pacheco, Daniel; Araújo, Arnaldo de a. Captura de movimento e animação de personagens em jogos. Universidade Fumec e Universidade Federal de Minas Gerais. Rio de Janeiro - RJ, 2009.

Laureano, Marcos. Estrutura de dados com algoritmos e c. Curitiba: Brasport livros e multimídia ltda, 2012.

Medeiros, Anna Carolina Soares. Interação natural baseada em gestos como interface de controle para modelos tridimensionais. Universidade Federal da Paraíba. João Pessoa, 2012.

Microsoft. Kinect for windows sdk. disponível em: < http://msdn.microsoft.com/enus/library/hh855347.aspx >. Acesso em: julho de 2014.

Pressman, Roger S. Software Engineering: A Practitioner`s Approach. 3. ed. McGrawHill, 1992.

Siga. Sistema de Informações de Gestão Acadêmica. Disponível em: https://sia.ufmt.br/www-siga/htmldelphi/login/LoginUnico/login.htm. Acesso em: março de 2016.

Valli, a. Notes on natural interaction. 2005. 